Table 1. Clinical, laboratory and lung functions tests of patients treated with RTX-B. Data expressed as mean \pm SD. FVC=forced vital capacity $(\%$ predicted $) ;$ TLC=total lung capacity $(\%$ predicted); DLCO=diffusion lung CO(\% predicted); DAS28=disease activity score 28 (3 RTX$\mathrm{Bn}, 3$ RTX-Bs) patients with arthritis);ESR(mm/1h).

\begin{tabular}{lccc}
\hline Overall & Time $\mathbf{0}$ & $\mathbf{6}$ Months & $\begin{array}{c}\mathbf{p} \\
\text { value }\end{array}$ \\
\hline mRSS & $11.8 \pm 9.3$ & $8.8 \pm 7.7$ & $\mathbf{0 . 0 0 1}$ \\
FVC & $89.7 \pm 21.1$ & $92.8 \pm 20.4$ & 0.089 \\
TLC & $86.3 \pm 19.4$ & $87.9 \pm 18.9$ & 0.219 \\
DLCO & $62.3 \pm 21.0$ & $60.7 \pm 18.8$ & 0.542 \\
DAS28 & $3.6 \pm 1.1$ & $2.2 \pm 0.9$ & $\mathbf{0 . 0 2 8}$ \\
ESR & $21.3 \pm 13.0$ & $16.9 \pm 9.7$ & $\mathbf{0 . 0 0 3}$ \\
RTX-Bn & & & \\
mRSS & $12.3 \pm 10.6$ & $9.2 \pm 8.3$ & $\mathbf{0 . 0 1 1}$ \\
FVC & $91.3 \pm 22.3$ & $95.3 \pm 18.8$ & 0.100 \\
TLC & 89.60 & $93.3 \pm 18.5$ & 0.172 \\
& \pm 21.16 & & \\
DLCO & $67.5 \pm 19.1$ & $64.3 \pm 15.4$ & 0.422 \\
DAS28 & $4.3 \pm 0.4$ & $2.1 \pm 1.1$ & 0.109 \\
ESR & $21.9 \pm 14.8$ & $17.4 \pm 11.2$ & $\mathbf{0 . 0 1 7}$ \\
RTX-Bs & & & \\
mRSS & $11.0 \pm 7.8$ & $8.2 \pm 5.9$ & $\mathbf{0 . 0 4 6}$ \\
FVC & $87.6 \pm 20.4$ & $89.4 \pm 23.1$ & 0.546 \\
TLC & $82.1 \pm 17.4$ & $80.1 \pm 18.0$ & 0.750 \\
DLCO & 56.00 & 56.33 & 0.799 \\
DAS28 & \pm 22.54 & \pm 22.49 & \\
ESR & $3.0 \pm 1.3$ & $2.4 \pm 0.9$ & 0.109 \\
\hline
\end{tabular}

Disclosure of Interests: Corrado Campochiaro Consultant for: Dr Corrado Campochiaro received consultation honoraria from Pfizer., Giacomo De Luca Consultant for: Dr Giacomo De Luca received consultation honoraria from Pfizer and SOBI., Maria Grazia Lazzaroni: None declared, Silvia Laura Bosello: None declared, Maria De Santis: None declared, adriana cariddi: None declared, Carlo Selmi Grant/research support from: AbbVie, Janssen, MSD, Novartis, Pfizer, Consultant for: AbbVie, Alfa-Sigma, Biogen, Bristol-Myrs Squibb, Celgene, Eli-Lilly, Janssen, Merck Sharp and Dohme, Novartis, Pfizer, Roche, Sanofi-Genzyme, UCB, Speakers bureau: AbbVie, Alfa-Sigma, Biogen, Bristol-Myrs Squibb, Celgene, Eli-Lilly, Janssen, Merck Sharp and Dohme, Novartis, Pfizer, Roche, Sanofi-Genzyme, UCB, Elisa Gremese Consultant for: AbbVie, BMS, Celgene, Janssen, Lilly, MSD, Novartis, Sanofi, UCB, Roche, and Pfizer, Speakers bureau: BMS, Speakers bureau: Roche, Speakers bureau: AbbVie, BMS, Celgene, Janssen, Lilly, MSD, Novartis, Sanofi, UCB, Roche, and Pfizer, Paolo Airò: None declared, Marco Matucci-Cerinic Grant/research support from: Actelion, MSD, Pfizer, BMS, Chemomab, Sanipedia, Speakers bureau: Actelion, BMS; MSD, Janssen, Lorenzo Dagna Consultant for: Prof Lorenzo Dagna received consultation honoraria from Abbvie, Amgen, Biogen, Bristol-Myers Squibb, Celltrion, Novartis, Pfizer, Sanofi-Genzyme, and SOBI.

DOI: 10.1136/annrheumdis-2019-eular.6961

\section{FRI0303 THE EFFECTS OF RIOCIGUAT ON RAYNAUD'S PHENOMENON AND DIGITAL ULCERS IN PATIENTS WITH DIFFUSE SYSTEMIC SCLEROSIS: RESULTS FROM THE PHASE IIB RISE-SSC STUDY}

Dinesh Khanna ${ }^{1}$, Yannick Allanore ${ }^{2}$, Christopher Denton ${ }^{3}$, Masataka Kuwana ${ }^{4}$, Marco Matucci-Cerinic ${ }^{5}$, Janet Pope ${ }^{6}$, Janethe de Oliveria Pena ${ }^{7}$, Kaisa Laapas ${ }^{8}$, Zhen $\mathrm{Yao}^{9}$, Melanie Hemmrich ${ }^{10}$, Oliver Distler ${ }^{11}$. ${ }^{1}$ University of Michigan, Ann Arbor, MI, United States of America; ${ }^{2}$ Cochin Hospital, Paris, France; ${ }^{3}$ University College London, London, United Kingdom; ${ }^{4}$ Nippon Medical School, Tokyo, Japan; ${ }^{5}$ University of Florence, Florence, Italy; ${ }^{6}$ University of Western Ontario, Ontario, Canada; ${ }^{7}$ Bayer US LLC, Whippany, NJ, United States of America; ${ }^{8}$ StatFinn Oy, Espoo, Finland; ${ }^{9}$ Bayer Healthcare Co. Ltd, Beijing, China; ${ }^{10}$ Bayer AG, Wuppertal, Germany; ${ }^{11}$ University Hospital Zurich, Zurich, Switzerland

Background: Riociguat is a soluble guanylate cyclase stimulator approved for treatment of pulmonary arterial hypertension associated with connective tissue disease. Through its vasodilatory and anti-remodeling properties, it was predicted that riociguat might relieve Raynaud's phenomenon (RP) attacks and reduce net digital ulcer (DU) burden in patients with diffuse cutaneous systemic sclerosis (dcSSc).

Objectives: We present exploratory endpoints from the RISE-SSc study (NCT02283762) on the effects of riociguat on RP and DUs in early dcSSc patients.

Methods: RISE-SSc was a Phase Ilb, multicenter, randomized, doubleblind, placebo-controlled study. Inclusion criteria were: SSc fulfilling ACR/
EULAR criteria, diffuse cutaneous involvement, disease duration $\leq 18$ months, and modified Rodnan skin score 10-22 units. Patients were assigned to placebo or riociguat individually adjusted from $0.5 \mathrm{mg}$ up to $2.5 \mathrm{mg}, 3$ times daily. Exploratory efficacy endpoints included 1) change in Raynaud's attacks from baseline to Week 14, assessed by: Raynaud's condition score; patient/physician assessment of RP; attack symptoms, attack duration, and average number of attacks per day; and 2) change in net DU burden from baseline to Week 52, assessed by ulcer count, ulcer burden, and visual analog score for patient-reported severity. Blood samples for exploratory evaluation of biomarkers were taken on Day 0 , Week 14 and for discontinuation before Week 14

Results: 60 patients were treated with riociguat and 61 with placebo None of the effects of riociguat on RP or DUs were statistically significant vs placebo. However, there was a greater relative reduction in attack duration, attack frequency, pain, numbness, tingling, and patient/ physician global assessment in the riociguat group vs placebo, from baseline to Week 14. Reductions in net DU burden were $-0.09 \pm 0.50$ for riociguat and $-0.08 \pm 1.47$ for placebo (estimated treatment difference: $0.11[95 \% \mathrm{Cl}:-0.38,0.17 ; \mathrm{p}=0.44]$ ) at Week 52. At Week 14, 2 patients in the riociguat group and 6 in the placebo group had developed new DUs. At Week 52, 5 and 12 patients, respectively, had developed new DUs. The total numbers of new DUs were 4 and 6 with riociguat and placebo, respectively, at Week 14 , and 12 and 65 , respectively, at Week 52 (Figure). Riociguat was associated with reductions vs placebo in serum sPECAM-1 $(p=0.004)$ and $C X C L-4 \quad(p=0.008)$, potentially indicating anti-vasculopathy properties of riociguat.

Conclusion: Riociguat did not produce statistically significant changes in DUs. Riociguat may reduce the development of new DUs in patients with early dcSSc and may favourably improve cytokine vasculopathy.
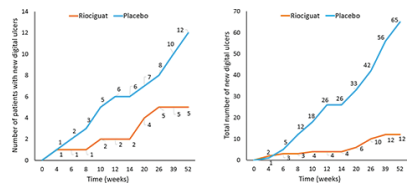

Figure. Development of new digital ulcers

Left: Number of patients with new digital ulcers

Right: Total number of new digital ulcers

New digital ulcers are defined as ulcers not existing at baseline.

Acknowledgement: Adelphi Communications Ltd, Bollington, UK provided medical writing support.

Disclosure of Interests: Dinesh Khanna Shareholder of: Eicos Sciences Inc, Grant/research support from: Bayer, BMS, Pfizer, Horizon, Consultant for: Actelion Acceleron, Arena, Bayer, BI, BMS, CSL Behring, Corbus, Cytori, GSK, Genentech/Roche, Galapagos, Employee of: Elcos Sciences, Inc, Yannick Allanore Grant/research support from: Inventiva, F Hoffman La-Roche, Sanofi, BMS, Pfizer, Consultant for: Actelion, Bayer, BMS, Boehringer, Roche, Sanofi, Christopher Denton Grant/research support from: GlaxoSmithKline, Inventiva, CSF Behring, Consultant for: RocheGenentech, Actelion, GlaxoSmithKline, Sanofi Aventis, Inventiva, CSL Behring, Boehringer Ingelheim, Bayer, Masataka Kuwana Grant/research support from: Actelion, Consultant for: Chugai, Reata, GlaxoSmithKline, Bayer, Boehringer-Ingelheim, Corpus, CSL-Berling, Mochida, Speakers bureau: Actelion, Pfizer, Bayer, Nippon Shinyaku, Chugai, Marco MatucciCerinic Grant/research support from: Actelion, MSD, Pfizer, BMS, Chemomab, Sanipedia, Speakers bureau: Actelion, BMS; MSD, Janssen, Janet Pope Consultant for: Eli Lilly and Company, Janethe de Oliveria Pena Employee of: Bayer, Kaisa Laapas Employee of: StatFinn Oy, partly insourced to Bayer, Zhen Yao Employee of: Bayer, Melanie Hemmrich Employee of: Bayer AG, Oliver Distler Grant/research support from: Prof Distler received research funding from Actelion, Bayer, Boehringer Ingelheim and Mitsubishi Tanabe to investigate potential treatments of scleroderma and its complications, Consultant for: Prof. Distler has/had consultancy relationship within the last 3 years with Actelion, AnaMar, Bayer, Boehringer Ingelheim, ChemomAb, espeRare foundation, Genentech/Roche, GSK, Inventiva, Italfarmaco, iQvia, Lilly, medac, Medlmmune, Mitsubishi Tanabe Pharma, Pharmacyclics, Novartis, Pfizer, Sanofi, Serodapharm and UCB in the area of potential treatments of scleroderma and its complications. In addition, he had/has consultancy relationship within the last 3 years with A. Menarini, Amgen, Abbvie, GSK, Mepha, MSD, Pfizer and UCB in the field of arthritides and related disorders DOI: 10.1136/annrheumdis-2019-eular.5755 